\title{
Study on process development and property evaluation of sol-gel derived magnesia stabilized zirconia minispheres
}

\author{
J. JUDES ${ }^{1 *}$, V. KAMARAJ ${ }^{2}$ \\ ${ }^{1}$ Department of Physics, University VOC college of Engg., Anna University, Tuticorin - 628008, India \\ ${ }^{2}$ Department of Ceramic Technology, Anna University, Chennai - 600025, India
}

\begin{abstract}
In order to overcome limitations in the processing parameters of powder compaction method, a novel processing technique based on sol-gel route has been developed to produce near-net-shaped prototype fine zirconia minispheres with required properties that could potentially be used as grinding media. Impact of magnesia concentration and sintering temperature on the final product has been analyzed in detail. Zirconia minispheres have been characterized to establish a correlation between physical, structural and mechanical properties. Sintering temperature, soaking period, heating rate and viscosity of the sol apparently influence the characteristics of the magnesia stabilized zirconia minispheres. The phase identification, density variation, chemical decomposition, functional group specification, surface area, porosity, shrinkage and microstructural features of the dried and sintered final product have been studied. It has been observed that magnesia content, sintering temperature, density and the grain size of the sintered minispheres have a significant impact on the mechanical properties of the final product.
\end{abstract}

Keywords: zirconia minispheres; sol-gel synthesis; zirconium oxalate sol; magnesia stabilization

(C) Wroclaw University of Technology.

\section{Introduction}

The conventional powder compaction method used for fabrication of grinding media (less than $1 \mathrm{~mm}$ in diameter) has major setbacks such as variety of size, density and non-uniformity in shape, since slight change in processing parameters leads to drastic structural changes. In order to overcome the limitations, a novel processing technique based on sol-gel drop generation method [1,2] has been developed in the present study to prepare nearnet-shaped nano-crystalline zirconia minispheres as grinding media. Sol-gel drop generation method is found to be very economical and effective. This method enables greater control of the process at the molecular level and avoiding impurities. Crystalline structures and catalytic properties can also be optimized. Among the ceramic oxides, zirconia is one of the most fascinating materials because of its excellent properties such as high fracture toughness, strength, stability in hostile envi-

\footnotetext{
*E-mail: taj_judes@yahoo.com
}

ronments etc. Various potential sol precursors were investigated and characterized for the preparation of zirconia minispheres as grinding media. The optimum was an aqueous sol made from hydrolyzed zirconium oxalate $\left(\mathrm{ZrO}(\mathrm{COO})_{2}\right)$ [3]. Sol-gel processing has the advantage of producing ultra-fine zirconia minispheres of required size by extruding zirconium oxalate sol.

To use zirconia to its full potential the properties of the oxide have been modified extensively by the addition of stabilizing oxides. One of the widely studied ceramic materials is magnesia stabilized zirconia $\left(\mathrm{Mg}-\mathrm{ZrO}_{2}\right) . \mathrm{Mg}-\mathrm{ZrO}_{2}$ received considerable attention in the literature for its dominant mechanical property, which is widely held to be transformation toughening during tetragonal to monoclinic transformation [4]. Structural and mechanical properties of magnesia stabilized zirconia can be easily tailored by systematic doping and temperature treatment, which makes the material very facile for the use as a grinding medium [5].

In general, zirconia can be synthesized using different methods. The traditional precipita- 
tion technique gives rise to microcrystalline zirconia, while the sol-gel method, produces nanocrystalline zirconia that is very attractive for novel applications since nanocrystalline structures often exhibit properties different from that observed in the microcrystalline ones. In the present study, the preparation of near-net-shaped prototype zirconia minispheres has been achieved by the sol-gel drop generation route. The characterization studies revealed the information about stabilization and enhancement of structural, physical and mechanical properties of zirconia minispheres.

\section{Experimental procedure}

Water soluble metal salts of chlorides and nitrates have been selected because compared with the alkoxides, the cost of the salts of inorganic material is quite low and hence the final product is cost effective. The starting material used for the preparation of zirconia sol was zirconium oxychloride octahydrate $\left(\mathrm{ZrOCl}_{2} \cdot 8 \mathrm{H}_{2} \mathrm{O}\right)$ of $1 \mathrm{M}$ concentration. Oxalic acid $\left((\mathrm{COOH})_{2} \cdot 2 \mathrm{H}_{2} \mathrm{O}\right)$ was refluxed in deionised water at $60{ }^{\circ} \mathrm{C}$ to obtain $1 \mathrm{M}$ concentration solution.

Magnesium nitrate hexahydrate $\left(\mathrm{Mg}\left(\mathrm{NO}_{3}\right)_{3} \cdot 6 \mathrm{H}_{2} \mathrm{O}\right)$ was used as a stabilizing agent to study the effect of transformation toughening property and processing conditions. The magnesium nitrate was stirred and mixed thoroughly with the solution of zirconyl chloride $(1 \mathrm{M})$ as a parent sol in such a way that the final sintered product contained 5, 8 and $10 \mathrm{~mol} \%$ of magnesia stabilized zirconia $\left(\mathrm{Mg}-\mathrm{ZrO}_{2}\right)$.The desired quantity (1:0.7 vol/vol ratio) of oxalic acid was then added dropwise, under constant stirring, to the parent sol at room temperature $\left(\sim 29{ }^{\circ} \mathrm{C}\right)$, which produced white flocculates and disappeared immediately [6]. The addition of stoichiometric ratio of oxalic acid with the mixed cation solution led to the formation of an unclear sol that then turned to be a white opaque gel. On the other hand, a transparent sol and gel were observed when the addition of oxalic acid was sufficient to form the magnesia doped zirconyl oxalate (MZO) gel. In order to understand more clearly the nature of dopants in the oxalate sols structure, Tohge et al. suggested that the dopant was uniformly distributed on the porous surface of the zirconyloxalate gel structure. During calcinations the dopant ions were substituted for zirconium ions in the crystal structure which favored the formation of the stabilized zirconia [7].

As the addition of oxalic acid was continued, the rate of disappearance of white flocculates decreased and finally a white opaque gel was obtained. The gel transformed into a clear sol on continuous stirring. A probable reason for the variation of the rate of disappearance of the flocculates might be the higher ionic concentration of the solution and an uneven distribution of the ions. As the time increased, the clear gel again became slightly opaque. The formed sol was transformed into a transparent thixotropic gel at room temperature by physical gelation. Since many factors influenced the solutions, a possible qualitative explanation for the disappearance of the white flocculates at the beginning stage, the formation of the white thick gel at the middle stage and the clear sol at the final stage, can be discussed on the basis of DLVO theory presented by Li and Messing [8].

It had also been noticed that the atmospheric conditions had a remarkable effect on the formation of the transparent sol, gel and gelation time. For example, if the humidity of the atmosphere was more than $95 \%$, the formed sol and gel were highly transparent at room temperature and the time taken for gelation was longer and if the humidity was less than $90 \%$, the formed sol was of aggregative nature and the gel was opaque. The viscosity measurements of the sol as a function of time were carried out using Brookfield viscometer which indicated that the viscosity of the sol increased with time. The gradual increase in the viscosity was due to the transformation of the particles from randomly aggregated state to ordered state with parallel orientation. The required viscosity could be obtained by adding a suitable binder, polyvinyl alcohol PVA (35 wt.\%) based on the formation of a sphere in the setting solution and retention of the shape after sintering. It might be considered that the formed hydrochloric acid was one of the reasons for the co- 
agulation and the formation of the thick gel during the preparation of pure zirconyl oxalate gel [9].

A $500 \mathrm{ml}$ beaker filled with $400 \mathrm{ml}$ of ammonia solution was taken as the spheres container. At a suitable viscosity, the mixed gel was added dropwise to a gelation container for the formation of uniform minispheres. The spheres were then dried at room temperature for 24 hours. The dried gel in the form of spheres was sintered at 300, 500, 700, $900,1100,1300$ and $1500{ }^{\circ} \mathrm{C}$ for 5 hours. Two heating rates (5 and $10{ }^{\circ} \mathrm{C} / \mathrm{min}$.) were employed to analyze the variations in crystallization temperature, particle size distribution and surface area. Fig. 1 shows the photograph of $8 \mathrm{Mg}-\mathrm{ZrO}_{2}$ dried and sintered minispheres. There was very little difference between the 2 and 5 hours sintered samples. Callon C.J. et al. also suggested that a longer sintering time had no effect on the degree of crystallinity [10]. The samples were characterized using a thermal analyzer (NETZSH STA 409PC), X-ray diffractometer with $\mathrm{Cu} \mathrm{K} \alpha$ radiation (SHIMADZU XD-DI) and Fourier transform infrared spectrometer by the $\mathrm{KBr}$ method (PERKIN-ELMER RXI). The BET (Brunauer-Emmett-Teller) method based on the physical adsorption of gas (nitrogen) on the solid surface was used to determine the surface area, pore size and pore volume. Density of minispheres was estimated using specific gravity bottle method. Theoretical density (TD) of minispheres was calculated using the rule of mixtures. The porosity details were calculated from the shrinkage data estimated from TGA data. Percentage of weight loss in minispheres after milling was calculated by using a sensitive electronic balance (resolution: $10 \mathrm{mg}$ ).

\section{Results and discussion}

\subsection{Thermal analysis}

Weight loss and phase transformation behaviour of dried $8 \mathrm{~mol} \%$ magnesia stabilized zirconia $\left(8 \mathrm{Mg}-\mathrm{ZrO}_{2}\right)$ minispheres in sintering process were identified by TGA-DTA analysis (Fig. 2). From the TGA curve of dried spheres, it can be observed that there are three major weight losses of $10.50 \%, 10.08 \%$ and $18.91 \%$. The first one is due to the dehydration of physisorbed water and the

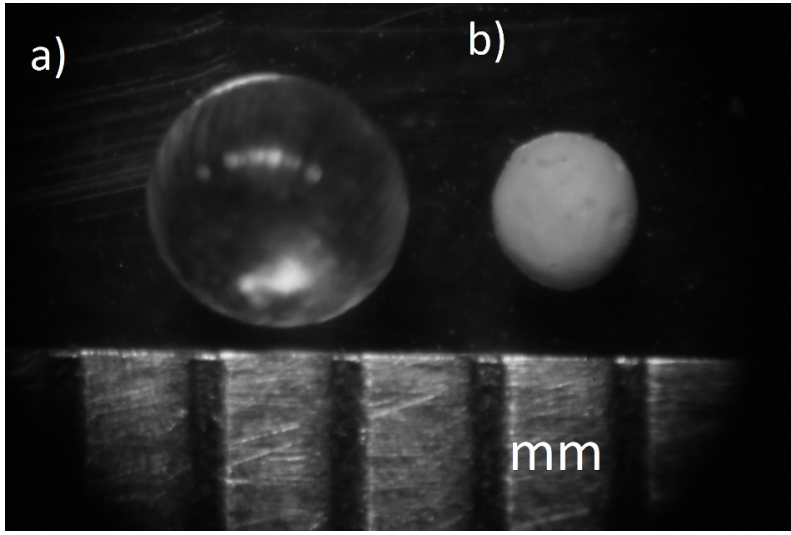

Fig. 1. Photograph of $8 \mathrm{~mol} \%$ magnesia stabilized zirconia $\left(8 \mathrm{Mg}-\mathrm{ZrO}_{2}\right)$ minispheres (a) dried at $40{ }^{\circ} \mathrm{C}$ (b) sintered at $1500{ }^{\circ} \mathrm{C}$.

second corresponds to the decomposition of nitrate. The third weight loss may be due to the oxalate decomposition followed by the binder burnout. The difference in the weight loss and shrinkage compared with the previous works could be due to the difference in concentration of sols prior to spinning, an unavoidable feature in this small scale development process. The average total weight loss of the sample with binder is higher than that of the sample without binder addition. The final weight of the sphere is found to be around $51 \%$ of the initial value. The percentages of weight losses with respect to temperature are listed in Table 1.

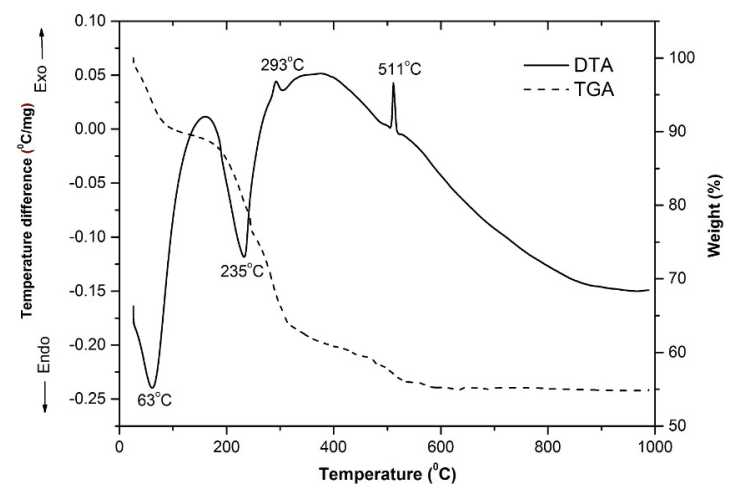

Fig. 2. TG-DTA curves for $8 \mathrm{Mg}-\mathrm{ZrO}_{2}$ minispheres dried at $40{ }^{\circ} \mathrm{C}$.

Fig. 2 shows the DTA curve for the dried sphere on which there are two endothermic and two exothermic peaks corresponding to temperatures 
around $63.34{ }^{\circ} \mathrm{C}, 235.09^{\circ} \mathrm{C}, 292.88^{\circ} \mathrm{C}$ and $511^{\circ} \mathrm{C}$. Two endothermic peaks at around 63 and $235^{\circ} \mathrm{C}$ may be due to the removal of bound water as well as some organics and nitrate decomposition. The decomposition of oxalate is evident as exothermic peak at around $293{ }^{\circ} \mathrm{C}$. Burning of binder is identified at around $305{ }^{\circ} \mathrm{C}$ without a prominent peak, which may be due to the smooth release of the binder. The initiation of crystallization is indicated by a sharp exothermic peak at around $511^{\circ} \mathrm{C}$ which is attributed to a phase change from amorphous zirconia to a metastable tetragonal phase. The thermal analysis data in the present study are very close to the reports of Chakarabarty et al. [11] To calculate the estimated porosity, it is assumed that the shrinkage occurs uniformly in all the three dimensions of the individual minispheres. The estimated porosity is then calculated from the equation:

$$
P=1-\left(\frac{1-S}{1-S_{T}}\right)^{3}
$$

where, $\mathrm{S}_{T}$ - percentage of linear shrinkage measured at a given temperature, $\mathrm{S}$ - total percentage of linear shrinkage for fully sintered material, $\mathrm{P}$ - percentage of calculated porosity. This method provides only an estimate, with the error becoming greater as porosity increases and is unreliable for values of $\mathrm{S}<0.5 \mathrm{~S}_{T}$.

Variations in percentage of weight loss, shrinkage and porosity with gradual rise in sintering temperature are compared and listed in Table 1. The shrinkage and weight loss variations are found to be minimum above $800{ }^{\circ} \mathrm{C}$. Reduction in the porosity value is found to be gradual. The porosity details are estimated from the shrinkage data, by assuming that there is no further shrinkage above $1500{ }^{\circ} \mathrm{C}$ and the porosity values above $1500{ }^{\circ} \mathrm{C}$ are underestimated [12].

\subsection{Effect of heating rate and soaking time}

Fast heating rate $\left(10^{\circ} \mathrm{C} / \mathrm{min}\right)$ has a huge impact on the weight loss at the water removal stage by nearly $50 \%$ compared with the slow heating rate $\left(5{ }^{\circ} \mathrm{C} / \mathrm{min}\right.$ ). In addition, it is observed that the increase in heating rate leads to the increase in crys- tallization temperature, wide particle size distribution and decrease in surface area (Table 2). Low heating rate $\left(5^{\circ} \mathrm{C} / \mathrm{min}\right)$ produces the maximum surface area and narrow particle size distribution. The crystallization temperatures and surface area are found to be strongly dependent on the heating rate. It is observed that the particle size of $13 \mathrm{~nm}$ can be obtained via decomposition of the oxalate at a heating rate at around $5{ }^{\circ} \mathrm{C} / \mathrm{min}$. For fast heating rates of $10{ }^{\circ} \mathrm{C} / \mathrm{min}$., the temperature at which zirconia synthesis is completed is higher and the time required for oxalate decomposition is shorter. During fast heating regimes, the surface area of the powder has no time to develop and the temperature becomes appropriate for the formation of presintered agglomerates of coarser primary particles. The temperature of crystallization in such heating regimes is $533-542{ }^{\circ} \mathrm{C}$. This high temperature of synthesis can be used to obtain aggregated powders.

The slow heating rate of $5-7{ }^{\circ} \mathrm{C} / \mathrm{min}$ gives much better final density of magnesia stabilized zirconia minispheres. In order to study the effect of soaking rate on the sinterability, soaking periods of 3 and 5 hours have been adopted. From Table 3, it is observed that the density of the sample sintered at slow heating rate reaches around $94 \%$ of theoretical density (TD) for a soaking period of 5 hours whereas the density of the fast fired sample reaches only around $89 \%$ of TD for the same period of soaking. The same trend has been observed for the samples with a soaking period of 3 hours also. The slow heating rate facilitates in achieving the highest density.

\subsection{Surface area analysis}

Specific surface area was estimated for $8 \mathrm{Mg}-\mathrm{ZrO}_{2}$ using BET technique with nitrogen. The dried gel powders were sintered at different temperatures of $450,550,700$ and $850{ }^{\circ} \mathrm{C}$ for $3 \mathrm{~h}$. The average crystallite sizes of $8 \mathrm{Mg}-\mathrm{ZrO}_{2}$ were calculated by assuming the particles to be spherical in shape as per the formula:

$$
r=\frac{3}{\gamma \rho} \mathrm{nm}
$$


Table 1. Variations in percentage of weight loss, shrinkage, theoretical density and porosity as a function of sintering temperature for $8 \mathrm{Mg}-\mathrm{ZrO}_{2}$ minispheres.

\begin{tabular}{|c|c|c|c|c|c|c|}
\hline $\begin{array}{l}\text { Temp. } \\
\left({ }^{\circ} \mathbf{C}\right)\end{array}$ & $\begin{array}{c}\text { Shrinkage } \\
(\%)\end{array}$ & $\begin{array}{c}\text { Wt. loss } \\
(\%)\end{array}$ & $\begin{array}{c}\text { Porosity } \\
(\%)\end{array}$ & $\begin{array}{l}\text { Density of sintered } \\
\text { spheres }\left(\mathrm{g} / \mathrm{cm}^{-3}\right)\end{array}$ & $\begin{array}{l}\text { Theoretical } \\
\text { density (\%) }\end{array}$ & $\begin{array}{l}\text { Avg. crystallite } \\
\text { size (nm) }\end{array}$ \\
\hline 300 & 26.36 & 33.77 & 69.66 & $\mathrm{n} / \mathrm{a}$ & $\mathrm{n} / \mathrm{a}$ & $\mathrm{n} / \mathrm{a}$ \\
\hline 500 & 32.84 & 42.31 & 60.01 & 4.27 & 77.46 & 17.83 \\
\hline 700 & 41.39 & 45.01 & 39.83 & 4.69 & 85.09 & 19.54 \\
\hline 900 & 45.82 & 47.56 & 23.83 & 5.15 & 92.8 & 25.27 \\
\hline 1100 & 47.28 & 48.12 & 17.33 & 4.87 & 88.35 & 55.94 \\
\hline 1300 & 50.19 & 48.89 & 1.97 & 4.93 & 89.44 & 57.68 \\
\hline 1500 & 50.52 & 49.42 & $\sim 0.0$ & 5.18 & 93.98 & 63.82 \\
\hline
\end{tabular}

Table 2. Effect of heating rate on surface area, particle size distribution, crystallization temperature and percentage of weight loss by water removal for $8 \mathrm{Mg}-\mathrm{ZrO}_{2}$ minispheres sintered at $1500{ }^{\circ} \mathrm{C}$.

\begin{tabular}{|c|c|c|c|c|}
\hline $\begin{array}{c}\text { Heating rate } \\
\left({ }^{\circ} \mathrm{C} / \mathrm{min}\right)\end{array}$ & $\begin{array}{l}\text { Surface area } \\
\left(\mathrm{m}^{2} / \mathrm{gm}\right)\end{array}$ & $\begin{array}{c}\text { Weight loss - water } \\
\text { removal }(\%)\end{array}$ & $\begin{array}{c}\text { Particle size } \\
\text { distribution }(\mathrm{nm})\end{array}$ & $\begin{array}{c}\text { Crystallization } \\
\text { temperature }\left({ }^{\circ} \mathrm{C}\right)\end{array}$ \\
\hline 5 & 7.6 & 10.5 & 13 & 511 \\
\hline 7 & 6.9 & 8.9 & 25 & 527 \\
\hline 8 & 6.3 & 6.8 & 61 & 533 \\
\hline 10 & 4.2 & 5.6 & 83 & 542 \\
\hline
\end{tabular}

Table 3. Effect of heating rate and soaking time on the density of $8 \mathrm{Mg}-\mathrm{ZrO}_{2}$ minispheres sintered at $1500{ }^{\circ} \mathrm{C}$.

\begin{tabular}{cccc}
\hline $\begin{array}{c}\text { Heating } \\
\text { rate }\end{array}$ & $\begin{array}{c}\text { Soaking period } \\
\text { (hours) }\end{array}$ & $\begin{array}{c}\text { Density } \\
(\mathbf{g} / \mathbf{c c})\end{array}$ & $\begin{array}{c}\text { Theoretical } \\
\text { density }(\%)\end{array}$ \\
\hline \hline Slow & 3 & 5.02 & 91.07 \\
$\left(5^{\circ} \mathrm{C} / \mathrm{min}\right)$ & 5 & 5.18 & 93.98 \\
\hline Fast & 3 & 4.81 & 87.26 \\
$\left(10^{\circ} \mathrm{C} / \mathrm{min}\right)$ & 5 & 4.93 & 89.44 \\
\hline
\end{tabular}

where $r$ is the average particle size (radius) in $\mathrm{nm}$, $\gamma$ is the specific surface area in $\mathrm{m}^{2} \mathrm{gm}^{-1}$ and $\rho$ is the density of the corresponding sintered powder in $\mathrm{g}^{-3}$. Table 4 shows the experimental data obtained for surface area, crystallite size and density with variation of sintering temperature. It is found that the surface area decreases as the sintering temperature increases due to the increase of the crystallite size. It can also be observed that the density and crystallite size increase with temperature as surface area decreases. The effect of magnesia concentration on the specific surface area, average pore diameter and specific pore volume of the composites are compared in Table 5.

\subsection{XRD analysis}

The effect of magnesia concentration and sintering temperature on phase composition of the zirconia minispheres have been analyzed by XRD analysis.

Fig. 3 shows the X-ray diffraction patterns of 5 and $10 \mathrm{~mol} \%$ magnesia stabilized zirconia sintered at $1500{ }^{\circ} \mathrm{C}$ for 5 hours. It is observed that the XRD patterns of $5 \mathrm{~mol} \%$ magnesia stabilized zirconia minispheres $\left(5 \mathrm{Mg}-\mathrm{ZrO}_{2}\right)$ sintered at $1500{ }^{\circ} \mathrm{C}$ is dominated by tetragonal phase with 0.41 fraction of monoclinic phase. With increasing magnesia content, the monoclinic phase of zirconia is 
Table 4. Variation of surface area of $8 \mathrm{Mg}-\mathrm{ZrO}_{2}$ as a function of temperature.

\begin{tabular}{cccc}
\hline $\begin{array}{c}\text { Firing } \\
\text { temp. }\left({ }^{\circ} \mathbf{C}\right)\end{array}$ & $\begin{array}{c}\text { Specific surface } \\
\text { area }\left(\mathbf{~ m}^{\mathbf{2}} \mathbf{g}^{\mathbf{- 1}}\right)\end{array}$ & $\begin{array}{c}\text { Density } \\
(\mathbf{g} / \mathbf{c c})\end{array}$ & $\begin{array}{c}\text { Average crystallite } \\
\text { size }(\mathbf{n m})\end{array}$ \\
\hline \hline 450 & 40.8 & 4.19 & 17.5 \\
550 & 37.2 & 4.31 & 18.7 \\
700 & 32.8 & 4.69 & 19.5 \\
850 & 25.9 & 4.93 & 23.5 \\
\hline
\end{tabular}

found to decrease. When the magnesia concentration reaches $10 \mathrm{~mol} \%$, monoclinic phase of zirconia disappears and zirconia is completely stabilized in the tetragonal phase. The above result demonstrates that the doping of magnesia to zirconia can be feasible for the monocrystalline phase. So, it is ascertained that the crystalline phase is highly related to the dopant ratio of magnesia to zirconia. Further increase in concentration may lead to the introduction of cubic phase as observed by Bhuvaneswari [13].

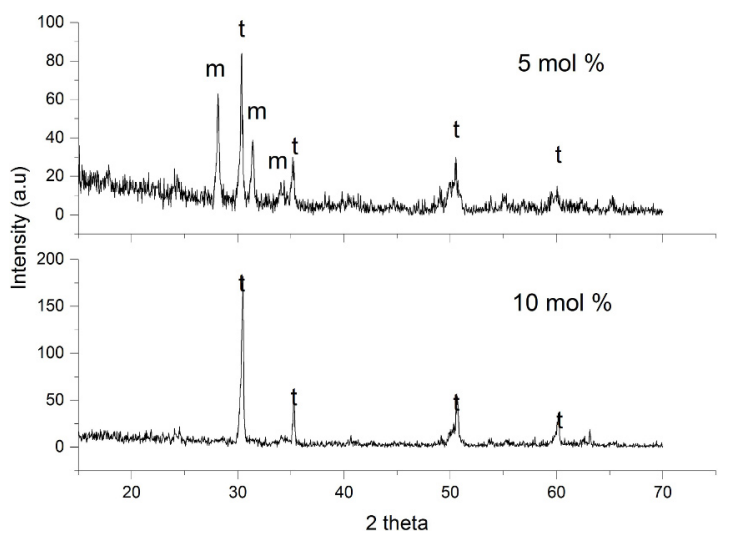

Fig. 3. XRD patterns for magnesia stabilized zirconia minispheres with magnesia concentrations: $5 \mathrm{~mol} \%$ and $10 \mathrm{~mol} \%$, sintered at $1500{ }^{\circ} \mathrm{C}$ for 5 hours.

XRD patterns of $8 \mathrm{~mol} \%$ magnesia stabilized zirconia $\left(8 \mathrm{Mg}-\mathrm{ZrO}_{2}\right)$ minispheres obtained at varying sintering temperature up to $1500{ }^{\circ} \mathrm{C}$, at a heating rate of $5{ }^{\circ} \mathrm{C} / \mathrm{min}$, are shown in Fig. 4 . $8 \mathrm{Mg}-\mathrm{ZrO}_{2}$ minispheres crystallize in tetragonal phase at $511{ }^{\circ} \mathrm{C}$. The retention of tetragonal phase is observed up to $900{ }^{\circ} \mathrm{C}$. It is observed that the amorphous zirconia transforms to the tetragonal phase around $511{ }^{\circ} \mathrm{C}$ depending on the ef- fective free energy change between tetragonal and monoclinic phases and nonchemical energies associated with the nucleation of monoclinic phase. The change in phase from pure tetragonal zirconia to pure monoclinic zirconia is evident between the temperatures ranging from 1100 to $1300{ }^{\circ} \mathrm{C}$. The spheres sintered at $1500{ }^{\circ} \mathrm{C}$ reveal the partial retention of tetragonal phase. The partial tetragonal transformation was also reported by Ding et al. [14]. The monoclinic phase concentration at $1500{ }^{\circ} \mathrm{C}$ is less than $37 \%$ which is different from previous reports where the low-temperature monoclinic phase transformed to the tetragonal and then into cubic phase at much higher temperature. In the present investigation, the samples contain both tetragonal and monoclinic phases without cubic phase at higher sintering temperatures and phase transformation from tetragonal to monoclinic occurs during sintering.

The same behaviour was also observed by Hannink [15]. This temperature range is suggested because $\mathrm{Mg}-\mathrm{ZrO}_{2}$ undergoes a eutectoid decomposition reaction below $1400{ }^{\circ} \mathrm{C}$ and heat treatment below $1400{ }^{\circ} \mathrm{C}$ should be avoided [15]. The increased crystallite size is reflected in XRD patterns as the decrease in the width of the dominant tetragonal line for higher values of sintering temperature. The crystallite size of $8 \mathrm{Mg}-\mathrm{ZrO}_{2}$ solid solution sintered at $1500{ }^{\circ} \mathrm{C}$ has been determined as $63 \mathrm{~nm}$ by using Scherer's and Warren's equations. When the tetragonal material reverts back to the monoclinic phase, the transformation results in micro cracking which weakens the sphere's strength.

\subsection{FTIR analysis}

IR spectrum for $8 \mathrm{Mg}-\mathrm{ZrO}_{2}$ solid solution dried at $40{ }^{\circ} \mathrm{C}$ and sintered at $1500{ }^{\circ} \mathrm{C}$ in the region of 


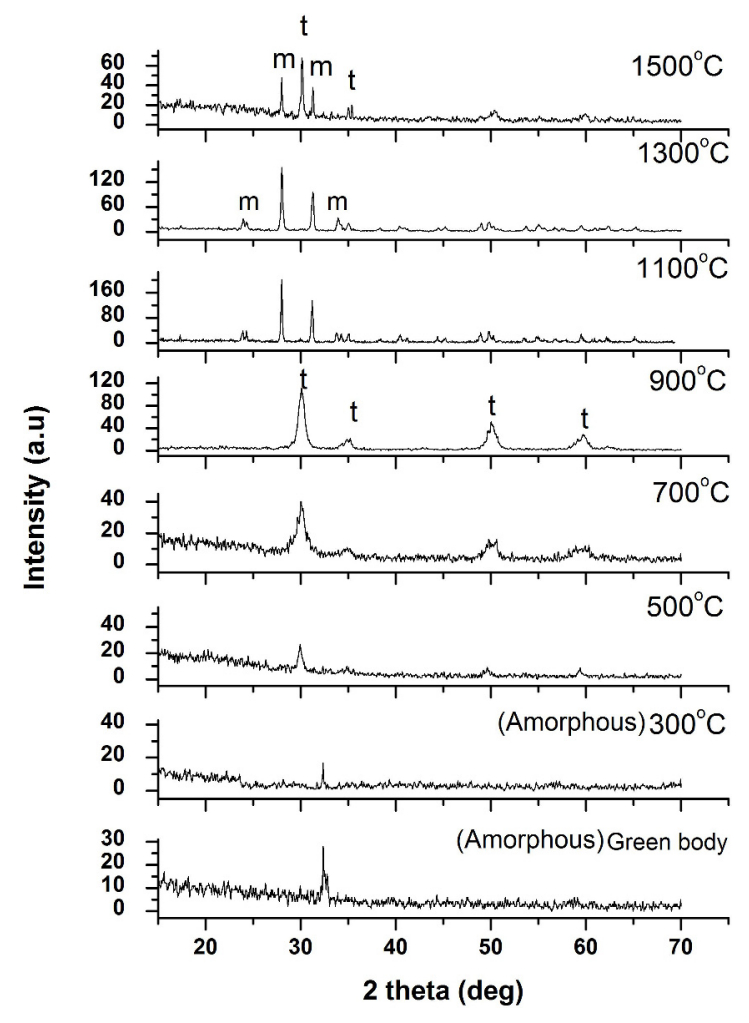

Fig. 4. XRD patterns for $8 \mathrm{Mg}-\mathrm{ZrO}_{2}$ minispheres obtained at various sintering temperatures $(\mathrm{t}-$ tetragonal, $\mathrm{m}$ - monoclinic).

$4000-400 \mathrm{~cm}^{-1}$ is shown in Fig. 5. The addition of magnesium ions has not affected the structure of the zirconyl oxalate which is evident by comparing with literature data on zirconyl oxalate gel [9].

The appearance of the peak at $1200 \mathrm{~cm}^{-1}$ is due to the presence of nitrates in the dried oxalate spheres. A well-defined characteristic absorption band at $494 \mathrm{~cm}^{-1}$ for both dried and sintered $\left(1200{ }^{\circ} \mathrm{C}\right)$ spheres confirms the $\mathrm{Zr}-\mathrm{O}-\mathrm{Zr}$ vibration. The peak at $3200 \mathrm{~cm}^{-1}$ shows the presence of $-\mathrm{OH}$ stretch. The peak at $795 \mathrm{~cm}^{-1}$ confirms the $(\mathrm{Zr}-\mathrm{O})+\delta(\mathrm{O}-\mathrm{C}=\mathrm{O})$ vibration. The presence and systematic removal of $\mathrm{H}_{2} \mathrm{O}$, binder, organic impurities and other volatile compounds are confirmed in FTIR spectrum for sintered spheres by the absence of peaks for $-\mathrm{OH},-\mathrm{C}-\mathrm{H}, \mathrm{C}-\mathrm{O}$ and $\mathrm{C}=\mathrm{O}$ groups. The above results are in good agreement with the previous studies $[9,16]$.

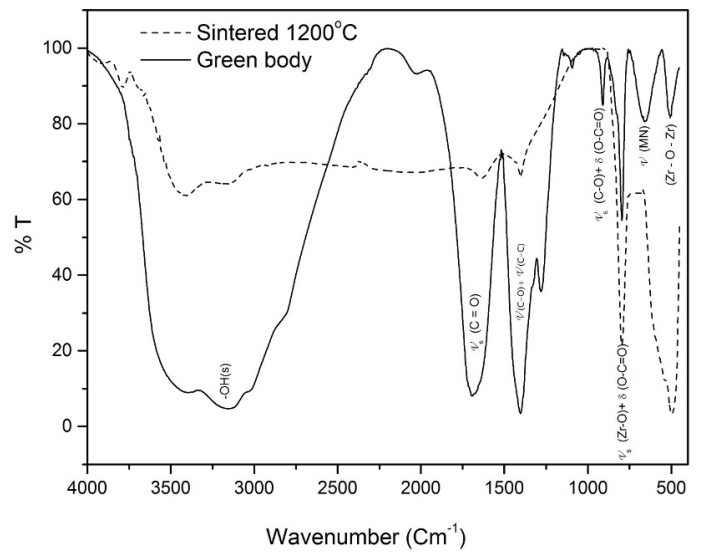

Fig. 5. FTIR spectrum of $8 \mathrm{Mg}-\mathrm{ZrO}_{2}$ minispheres.

\subsection{Density studies}

The density and average crystallite size variations with sintering temperature are illustrated in Fig. 6. The density is found to increase linearly with sintering temperature up to $900{ }^{\circ} \mathrm{C}$ where it reaches the value of $93 \%$ TD (Table 1). It is observed that the linear increase in the density with the sintering temperature is affected by the formation of monoclinic phase in minispheres sintered between $1100{ }^{\circ} \mathrm{C}$ and $1300{ }^{\circ} \mathrm{C}$ (Fig. 6). The variation of density values may be due to the volume expansion that takes place during phase transformation and also due to the formation of microcracks. Density reaches a maximum of $94 \%$ TD for minispheres sintered at $1500{ }^{\circ} \mathrm{C}$. Variation of density with magnesia concentration is also observed (Fig. 7). The density of the $\mathrm{Mg}-\mathrm{ZrO}_{2}$ minispheres sintered at $1500{ }^{\circ} \mathrm{C}$ is found to be increasing with magnesia concentration.

It is observed that there is a sharp increase in density for zirconia minispheres with $7 \mathrm{~mol} \%$ of magnesia concentration but further increase in magnesia leads to a gradual increase in density.

\subsection{Microstructural analysis}

Fig. 8 ( $a$ and $b$ ) show the SEM micrographs of $8 \mathrm{Mg}-\mathrm{ZrO}_{2}$ minispheres sintered at $900{ }^{\circ} \mathrm{C}$ and $1500{ }^{\circ} \mathrm{C}$. It is observed that the microstructures are almost similar for the minispheres sintered at $900{ }^{\circ} \mathrm{C}$ and $1500{ }^{\circ} \mathrm{C}$ except the reduction in porosity. 


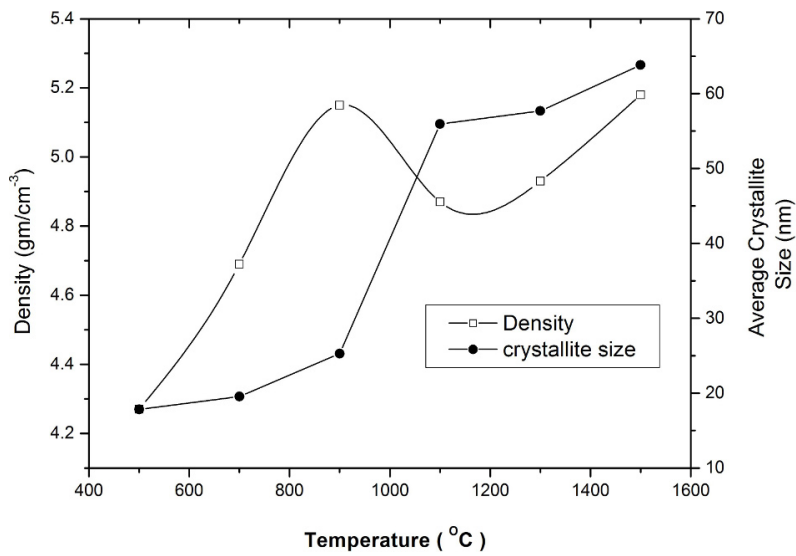

Fig. 6. Variation of density and average crystallite size with sintering temperature for $8 \mathrm{Mg}-\mathrm{ZrO}_{2}$ minispheres.

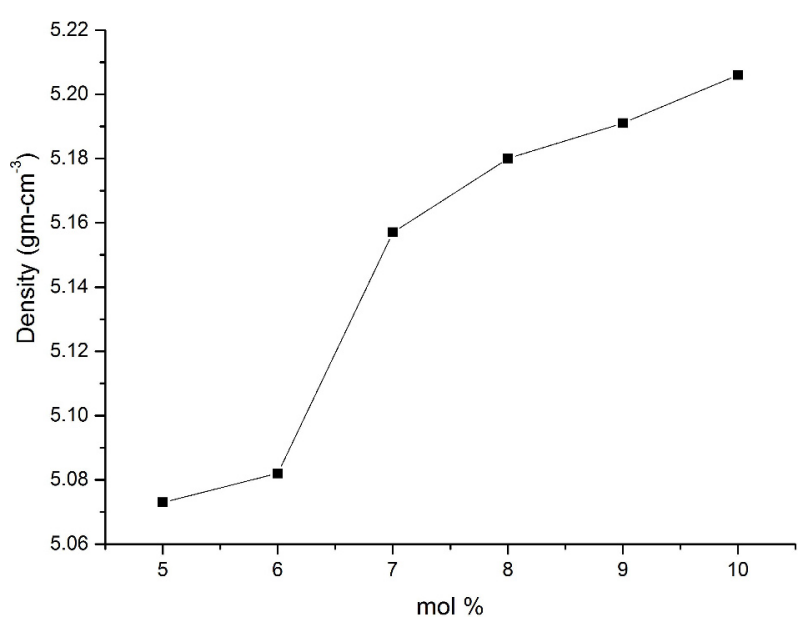

Fig. 7. Variation of density with magnesia concentration for minispheres sintered at $1500{ }^{\circ} \mathrm{C}$.

Non uniform grain growth is observed for all sintering temperatures. It is also observed that the existence of pores at the grain corners shows the inability to complete removal of pores even for the samples sintered at $1500{ }^{\circ} \mathrm{C}$. The existing pores at grain boundaries in early and intermediate stages are pulled together to form large pores at the final stage of sintering. The average grain size of $8 \mathrm{Mg}-$ $\mathrm{ZeO}_{2}$ minispheres sintered at $900{ }^{\circ} \mathrm{C}$ and $1500{ }^{\circ} \mathrm{C}$ for 5 hours are found to be 1.2 and $2.7 \mu \mathrm{m}$, respectively. Fig. 9 ( $a$ and $b$ ) show the SEM micrographs of zirconia minispheres stabilized with 5 and $10 \mathrm{~mol} \%$ of magnesia. The shape and size of grains are found to be drastically changed with the increase in magnesia content from 5 to $10 \mathrm{~mol} \%$.

Table 5. Variation of pore size, surface area and pore volume as a function of magnesia concentration for minispheres sintered at $1500{ }^{\circ} \mathrm{C}$.

\begin{tabular}{|c|c|c|c|}
\hline $\begin{array}{c}\text { Magnesia } \\
\text { content } \\
(\mathrm{mol} \%)\end{array}$ & $\begin{array}{c}\text { Surface } \\
\text { area } \\
\left(\mathrm{m}^{2} / \mathrm{g}\right)\end{array}$ & $\begin{array}{c}\text { Mean } \\
\text { pore size } \\
(\mathbf{n m})\end{array}$ & $\begin{array}{c}\text { Pore } \\
\text { volume } \\
(\mathrm{ml} / \mathrm{g})\end{array}$ \\
\hline 5 & 1.6 & 5.9 & 0.09 \\
\hline 8 & 25.9 & 6.6 & 0.12 \\
\hline 10 & 30.3 & 7.3 & 0.13 \\
\hline
\end{tabular}

In contrast to $5 \mathrm{Mg}-\mathrm{ZrO}_{2}$, the microstructure of $10 \mathrm{Mg}-\mathrm{ZrO}_{2}$ shows almost homogeneous microstructure with the lowest porosity. Surface morphologies of 8 and 10 mol \% magnesia stabilized zirconia minispheres sintered at $1500{ }^{\circ} \mathrm{C}$ are found to be uniform, compact, and crack free.

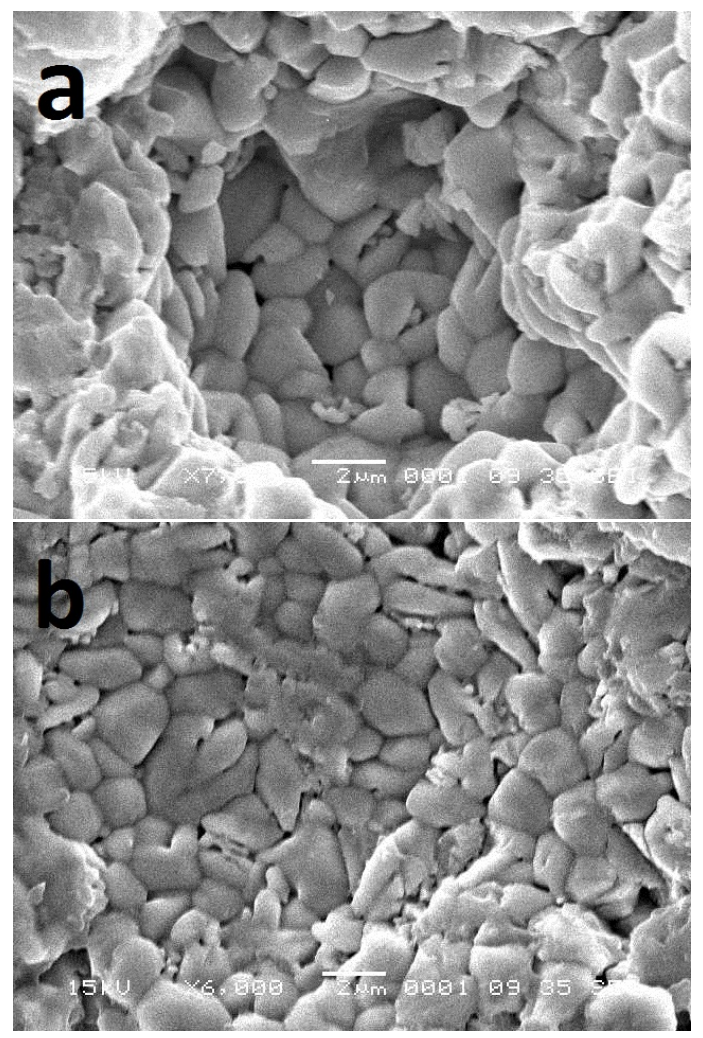

Fig. 8. SEM micrographs of $8 \mathrm{~mol} \%$ magnesia stabilized zirconia minispheres (a) sintered at $900{ }^{\circ} \mathrm{C}$ (b) sintered at $1500{ }^{\circ} \mathrm{C}$. 


\subsection{Mechanical properties}

Magnesia partially stabilized zirconia (Mg-PSZ) has received considerable attention in the literature for its high fracture toughness [5]. The mechanism responsible for the high toughness of Mg-PSZ is widely held to be transformation toughening from the tetragonal-to-monoclinic phase transformation. In order to determine the Vicker's hardness and fracture toughness, the minispheres were mounted on bakelite in a cylindrical mount and polished to get a glassy fractured surface. Optical photograph (Fig. 10) shows a typical indentation mark for $8 \mathrm{~mol} \%$ magnesia stabilized zirconia minisphere samples sintered at $1300{ }^{\circ} \mathrm{C}$ for an applied load of $2 \mathrm{~kg}$.

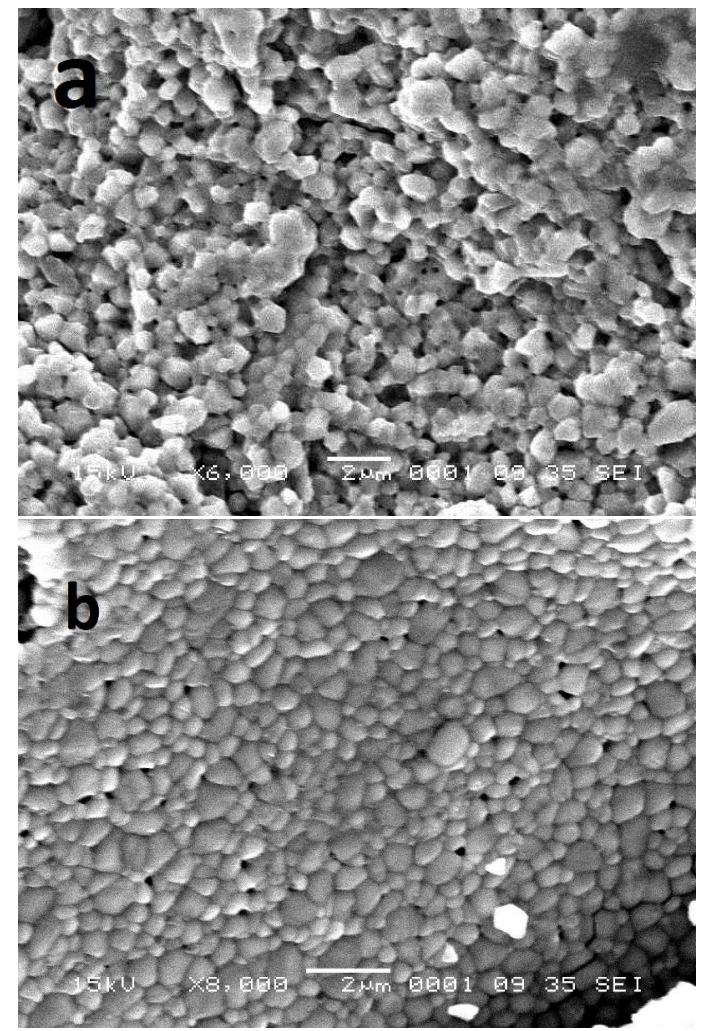

Fig. 9. SEM micrographs of magnesia stabilized zirconia minisphere with different magnesia concentrations sintered at $1500{ }^{\circ} \mathrm{C}$, (a) $5 \mathrm{Mg}-\mathrm{ZrO}_{2}$ (b) $10 \mathrm{Mg}-\mathrm{ZrO}_{2}$.

\subsubsection{Hardness}

Fig. 11 shows the variations of hardness, fracture toughness and grain size with respect to the increase in sintering temperature of minispheres. Hardness of $8.21 \mathrm{GPa}$ is observed for $8 \mathrm{Mg}-\mathrm{ZrO}_{2}$ minispheres sintered at $900{ }^{\circ} \mathrm{C}$ while further increase in temperature makes the hardness slightly decrease to $7.97 \mathrm{GPa}$ for minispheres sintered at $1300{ }^{\circ} \mathrm{C}$. Retention of tetragonal phase and better densification at $1500{ }^{\circ} \mathrm{C}$ supports improvement in the hardness to $8.09 \mathrm{GPa}$.

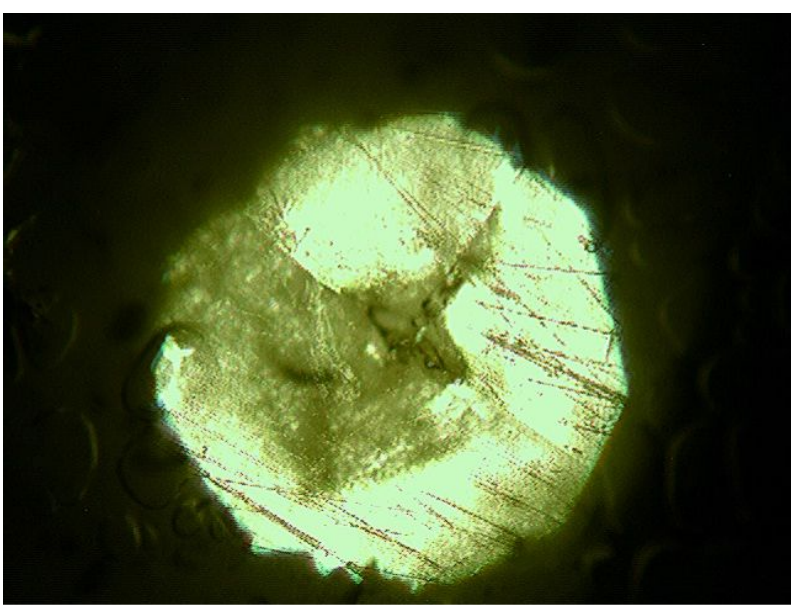

Fig. 10. Optical photograph of a typical indentation mark on the surface of $8 \mathrm{Mg}-\mathrm{ZrO}_{2}$ minispheres sintered at $1300{ }^{\circ} \mathrm{C}$ (applied load $2 \mathrm{~kg}$ ).

Increase in grain size, apart from the high fraction of monoclinic phase present in $8 \mathrm{Mg}-\mathrm{ZrO}_{2}$ minispheres sintered at $1500{ }^{\circ} \mathrm{C}$, may be the reason for the low hardness. Fig. 12 shows the increase in hardness with the increase in magnesia concentration. It has been observed that the stability of the tetragonal phase increased with the magnesia concentration (Fig. 3) which may restrict the tetragonal to monoclinic phase transformation and improve the density of sintered minispheres. This improvement in density of minispheres leads to the increase in hardness from 7.14 to $8.5 \mathrm{GPa}$ for the magnesia concentration ranging from 3 to $10 \mathrm{~mol} \%$.

It is observed that the hardness decreases with the increase of applied load, varying from $8.1 \mathrm{GPa}$ (applied load of $0.5 \mathrm{~kg}$ ) to $6.8 \mathrm{GPa}$ (applied load of $2 \mathrm{~kg}$ ) for $8 \mathrm{Mg}-\mathrm{ZrO}_{2}$ sintered at $1500{ }^{\circ} \mathrm{C}$ (Fig. 13). It is also observed that the hardness increases with the magnesia concentration for all values of applied load and reaches a maximum of $8.5 \mathrm{GPa}$ for $10 \mathrm{Mg}-\mathrm{ZrO}_{2}$ sintered at $1500{ }^{\circ} \mathrm{C} .5 \mathrm{Mg}-\mathrm{ZrO}_{2}$ has 


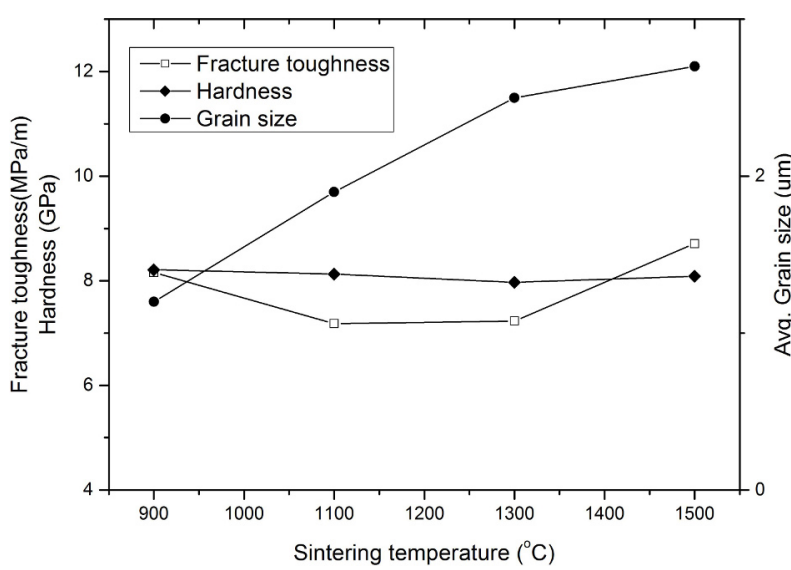

Fig. 11. Variations in hardness, fracture toughness and grain size of $8 \mathrm{Mg}-\mathrm{ZrO}_{2}$ minispheres with sintering temperature.

a low hardness of 5.4 GPa for the applied load of $2 \mathrm{~kg}$. Hardness is also found to be heavily dependent on the density of the minispheres. The low hardness possessed by $8 \mathrm{Mg}-\mathrm{ZrO}_{2}$ minispheres sintered at $1300{ }^{\circ} \mathrm{C}$ for an applied load of $2 \mathrm{~kg}$ is evident in Fig. 10 by the large and irregular size of indentation mark which may be due to domination of monoclinic phase and reduced density.

\subsubsection{Fracture toughness}

Fracture toughness $\left(\mathrm{K}_{I C}\right)$ of the sample was measured using the Vickers indentation technique. The fracture toughness of compacts depends upon the sintering temperature and crystalline phase formed in the system. Fig. 11 shows the fracture toughness values for $8 \mathrm{Mg}-\mathrm{ZrO}_{2}$ minispheres heattreated at different temperatures for the applied load of $0.5 \mathrm{~kg}$. It is well known that the toughening of $\mathrm{ZrO}_{2}$ ceramics with magnesia can be achieved through martensitic transformation from tetragonal to monoclinic phase. The fracture toughness of $8 \mathrm{Mg}-\mathrm{ZrO}_{2}$ minispheres sintered at $900{ }^{\circ} \mathrm{C}$ is found to be $8.16 \mathrm{MPa} \cdot \mathrm{m}^{\frac{1}{2}}$. As sintering temperature increases, unexpected decrease in fracture toughness value $\left(7.23 \mathrm{MPa} \cdot \mathrm{m}^{\frac{1}{2}}\right)$ is observed above $1100{ }^{\circ} \mathrm{C}$ which may be due to the lower density and complete monoclinic phase transformation. Increase in fracture toughness $\left(8.71 \mathrm{MPa} \cdot \mathrm{m}^{\frac{1}{2}}\right)$ is observed for $8 \mathrm{Mg}-\mathrm{ZrO}_{2}$ minispheres sintered at $1500{ }^{\circ} \mathrm{C}$ which may be due to the partial retention of transformable tetragonal phase.

Fig. 12 shows the variation of fracture toughness with magnesia concentration in zirconia minispheres sintered at $1500{ }^{\circ} \mathrm{C}$ for an applied load of $0.5 \mathrm{~kg}$. It is observed that the fracture toughness of $\mathrm{Mg}-\mathrm{ZrO}_{2}$ minispheres increases with the addition of magnesia up to $8 \mathrm{~mol} \%$ but further increase in magnesia content leads to the decrease in fracture toughness value, probably due to the presence of transformable tetragonal phase. The $5 \mathrm{~mol} \%$ magnesia composition has relatively low fracture toughness, apparently due to the large amount of monoclinic phase.

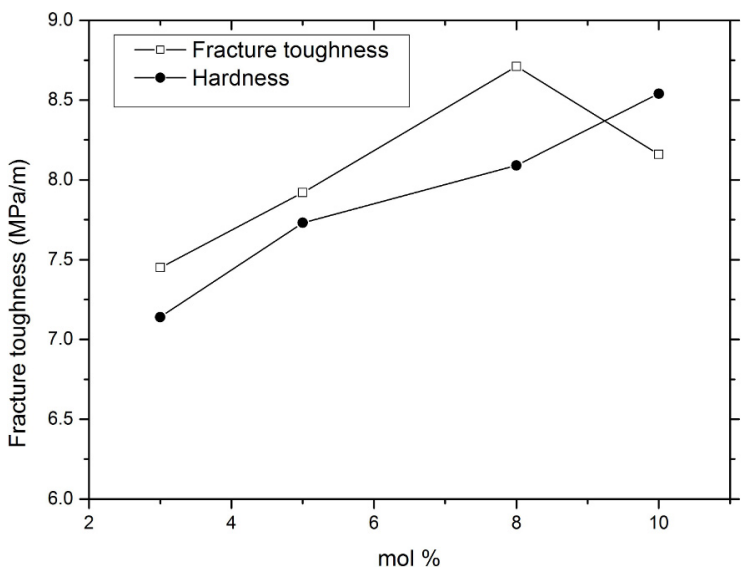

Fig. 12. Variations in hardness and fracture toughness with magnesia concentrations for $\mathrm{Mg}-\mathrm{ZrO}_{2}$ minispheres sintered at $1500{ }^{\circ} \mathrm{C}$ (applied load of $0.5 \mathrm{~kg}$ ).

\subsubsection{Wear resistance}

It is observed that the percentage of wear increases with milling time. The wear is $0.18 \%$ for a milling time of 3 hours and it increases to $0.41 \%$ for 9 hours of milling. It is observed that the wear resistance mainly depends on the amount of transformable tetragonal phase present in the sample. Zirconia minispheres stabilized with less than $5 \mathrm{~mol} \%$ of magnesia contain high fraction of monoclinic phase which in turn is responsible for the high value of wear loss. Percentage of wear loss is found to decrease considerably above $8 \mathrm{~mol} \%$ of magnesia concentration. Decrease in wear resistance is observed for $8 \mathrm{Mg}-\mathrm{ZrO}_{2}$ minispheres 
sintered between 1100 and $1300{ }^{\circ} \mathrm{C}$ since the minispheres sintered in this temperature range consist of complete monoclinic phase characterized by reduced density values. It is also observed that the $8 \mathrm{Mg}-\mathrm{ZrO}_{2}$ minispheres sintered below $700{ }^{\circ} \mathrm{C}$ do not withstand the milling operations.

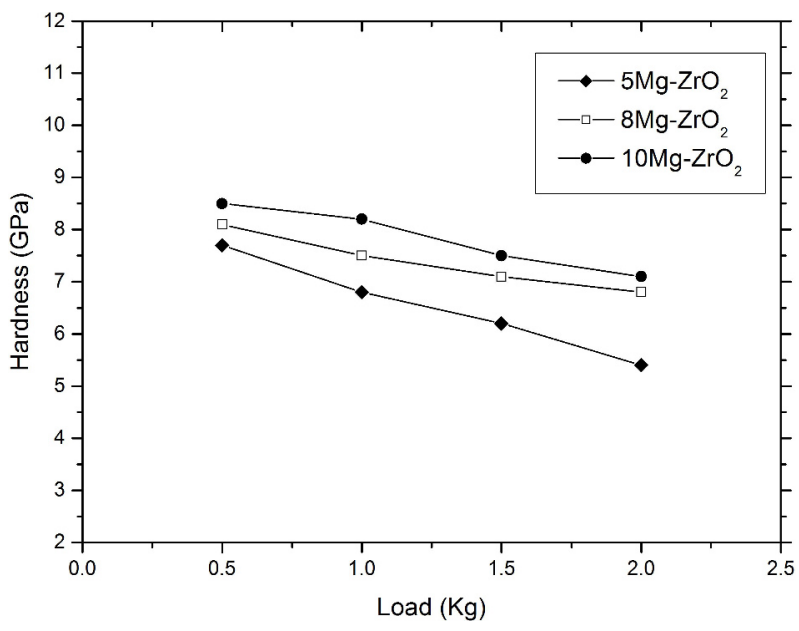

Fig. 13. Variation of Vickers hardness with applied load and magnesia concentrations in $\mathrm{Mg}-\mathrm{ZrO}_{2}$ minispheres sintered at $1500{ }^{\circ} \mathrm{C}$ for 5 hours.

\section{Conclusion}

Magnesia stabilized zirconia minispheres were prepared by sol-gel drop generation technique from zirconium oxalate sol. Effects of heating rate, soaking time and surface area on density of the magnesia stabilized minispheres were studied. The ideal sintering temperature for the preparation of sol-gel derived magnesia stabilized zirconia minispheres was $1500{ }^{\circ} \mathrm{C}$. The samples prepared at this temperature had partially stabilized tetragonal phase with $94 \%$ of theoretical density. Sintering temperature in the range of 1000 and $1300{ }^{\circ} \mathrm{C}$ led to the monoclinic phase transformation and subsequent reduction in density. Surface area, pore size, as well as pore volume of the zirconia minispheres increased with magnesia concentration and decreased with sintering temperature.

The presence and systematic removal of volatile compounds was observed by TGA/DTA analysis, which was then confirmed by FTIR studies. XRD studies revealed that the crystalline phases of magnesia stabilized zirconia transformed form amorphous to tetragonal and then to monoclinic phase with an increase in sintering temperature. Retention of partial tetragonal phase was observed at $1500{ }^{\circ} \mathrm{C}$. The effect of sintering schedule and stabilizer content on the mechanical properties of zirconia minispheres were analyzed in detail. It was observed that even though the hardness increased with the stabilizer content and density, it decreased with an increase in applied load. Fracture toughness was found to vary depending on the fraction of tetragonal phase present in the system. It was observed that the percentage of wear loss slightly increased with milling time and even after 9 hours of milling only negligible contamination was observed. It was also observed that the hardness and fracture toughness cannot be improved simultaneously.

\section{References}

[1] Judes J., Kamaraj V., J. Sol-Gel Sci. Techn., 49 (2009), 159.

[2] Judes J., Kamaraj V., Mater. Sci.-Poland, 27 (2) (2009), 407.

[3] Wang J.A., Valenzuela M.A., Salmones J., VAzQuez A., Garcia-Ruiz A., Bokhimi X., Catal. Today, 68 (2001), 21.

[4] Mcmeeking R. M., Evans A. G., J. Am. Ceram. Soc., 65 (5) (1982), 242.

[5] ZHI-Guo SHI., Li Xu., Micropor. Mesopor. Mat., 94 (2006), 34.

[6] Oleg Vasylkiv, Yoshio Sakka, J. Am. Ceram. Soc., 83 (9) (2000), 2196.

[7] Tohge N., Moore G.S., Mackenzie J.D., J. NonCryst. Solids, 63 (1984), 65.

[8] Li M., Messing L., Ceramic Transactions: Ceramic Powder Science III, American Ceramic Society, 1990, 129.

[9] Etienne J., Larbot A., Guizard C., Cot L., Alary J.A., J. Non-Cryst. Solids., 125 (1990), 224.

[10] Callon C.J., Goldie D.M., DibB H.F., Cairns J.A., PATON J., J. Mater. Sci. Lett., 19 (2000), 1689.

[11] Chakrabarty P.K., Chatterjee M., Naskar M.K., Siladitya B., Gangu D., J. Eur. Ceram. Soc., 21 (2001), 355.

[12] Pullar R.C, Taylor M.D., Bhattacharya A.K., J. Eur. Ceram. Soc., 21 (2001), 19.

[13] Bhuvaneswari M.S., SelvaseKarapandian S., VIJAYAKUMAR M., HIRANKUMAR G., RAMPRASAD G., Subramanian R., Angelo P.C., Ceram. Int., 30 (2004), 1631. 
[14] Ding J., Tsuzuki T., Mccormick P., Nanostruct. Mater., 8 (1997), 75.

[15] Hannink R.H.J., J. Mater. Sci., 18 (1983), 457.

[16] Porter D.L., Hever A.H., Acta Metall., 27 (1979), 1649.
[17] Gangadevi T., Subbarao M., Kutty T.R.N., Indian J. Chem. A, 19 (1980), 303.

Received 2012-03-01

Accepted 2014-03-22 